\title{
Testing for purchasing power parity for ASEAN-5 using asymmetric cointegration tests
}

\author{
Niri Martha Choji 1,2,*, Siok Kun Sek ${ }^{2}$ \\ ${ }^{1}$ Department of Mathematics, Plateau State University, Bokkos, Nigeria \\ ${ }^{2}$ School of Mathematical Sciences, Universiti Sains Malaysia, 11800 Minden, Penang, Malaysia
}

\section{A R T I C L E IN F O}

\section{Article history:}

Received 20 March 2017

Received in revised form

25 September 2017

Accepted 26 September 2017

\section{Keywords:}

Purchasing power parity

Asymmetric adjustment

Threshold autoregressive (TAR)

Model momentum threshold

autoregressive(MTAR)

\begin{abstract}
A B S T R A C T
This paper tries to examine if purchasing power parity exists in Indonesia, Malaysia, Philippines, Singapore, and Thailand. To this end, we conduct a nonlinear asymmetric cointegration approach on testing for the existence of purchasing power parity (PPP) in ASEAN-5 countries using the threshold cointegration tests (TAR and MTAR). Based on Monthly data from 1996 to 2016, results of the threshold cointegration tests revealed evidence of long run PPP with asymmetric adjustment in Philippines and Thailand. However, PPP does not hold in Indonesia, Malaysia and Singapore, and the adjustment process in these countries is symmetric.
\end{abstract}

(C) 2017 The Authors. Published by IASE. This is an open access article under the CC BY-NC-ND license (http://creativecommons.org/licenses/by-nc-nd/4.0/).

\section{Introduction}

The purchasing power parity theory, one of the oldest theories in the field of international finance states that the exchange rate between two countries should be equal to the ratio of the aggregate price levels between the two countries. Despite substantial empirical studies on the theory of PPP, research on the purchasing power parity is still being carried out because of its importance in policy implications in international trade and finance. Among the importance of PPP, is that it can be used to predict exchange rate to determine whether a currency is over-valued or under-valued. PPP is also used in measuring and comparing national income levels among countries. It is a tool used for forecasting general economic circumstances of countries (Beirne, 2010).

Because of its importance, considerable effort has been put into testing the validity of the long-run purchasing power parity. Countless researchers have utilized conventional linear unit root tests in real exchange rates, and cointegration between various measures of domestic and foreign prices and nominal exchange rates in the study of the long-run purchasing power parity (Su et al., 2010). The conclusions drawn from these studies are based on linear tests of unit roots and/ or cointegration. There is no reason to continue assuming that the long run

\footnotetext{
* Corresponding Author.
}

Email Address: marthaniri@yahoo.com (N. M. Choji) https://doi.org/10.21833/ijaas.2017.011.025

2313-626X/C 2017 The Authors. Published by IASE. This is an open access article under the CC BY-NC-ND license (http://creativecommons.org/licenses/by-nc-nd/4.0/)
PPP adjustment process towards equilibrium is symmetric since a lot of evidence supporting asymmetric reactions in key economic variables have been acknowledged (Lu et al., 2011). As shown by Bahmani-Oskooee et al. (2016), economic variables such as the exchange rate may follow an asymmetric adjustment process. The power of linear cointegration test is low in an asymmetric adjustment process. Enders and Granger (1998) showed that the standard tests of stationarity and cointegration have low power in the presence of misspecified dynamics (Lu et al. 2011).

Due to the importance of the purchasing power parity, many empirical analyses have been conducted using different methods in determining the validity of PPP theory for different countries. In an effort to finding more powerful tests, a number of researchers have considered tests of nonlinearity or asymmetry in testing economic variables. These researchers include Baum et al. (2001) who modelled the dynamics of adjustments to long run PPP over the post- Bretton Wood era in a nonlinear framework for a set of U.S. trading partners from the period of August, 1973 to December, 1995 using the exponential smooth transition autoregressive (ESTAR) model. They found support for a nonlinear dynamic structure with a very slow convergence to long run purchasing power parity in the postBretton Woods era. Furthermore, Chen et al. (2013) found out that cointegration adjustment between exchange rate and oil prices in Philippines from the period of 1970Q1-2011Q4 appear to be asymmetric with the use of the momentum threshold autoregressive (MTAR) model. But they got a contrary result when they applied the threshold 
autoregressive (TAR) model. Moreover, Haughton and Iglesias (2012) analysed asymmetric interest rates and the monetary transmission mechanism in the volatility on interest rates and the monetary transmission mechanism in the countries of Caribbean single market and economy (CSME) using monthly data from the period 1995 to 2010. The results of TAR and MTAR models showed asymmetric cointegration for Guyana, Jamaica and St. Lucia (but not for Barbados, Haiti, Trinidad and Tobago) for both lending and deposit rates. In addition, Khim and Liew (2004) in a paper titled "Nonlinear Adjustment of ASEAN-5 Real Exchange Rates; Symmetrical or Asymmetrical?" examined whether the nonlinear adjustment dynamics of exchange rate to the equilibrium level is symmetrical or asymmetrical using quarterly data from 1973Q1 to 1996Q4. They found out that the U.S. Dollar based real exchange rates of Indonesia, Philippines, Singapore and Thailand exhibit LSTAR-type nonlinearity, implying that the real exchange rates of these countries have asymmetric response towards appreciation and depreciation. In examining the stationarity of property of 11 Asian real exchange rates, Liew et al. (2004) found stationarity in most of the 11 Asian countries from the period of 1968Q1 to 2001Q2 when they applied the KSS (Kapetanios et al., 2003) nonlinear unit root test. Finally, Tiwari and Shahbaz (2014), examined the PPP hypothesis for India with her five major trading partners over the period of 1991M1-2009M2 using the DF-GLS unit root test and the threshold autoregressive (TAR) model as well as the momentum-TAR (M-TAR) models for the empirical analysis. Their analysis revealed that PPP hypothesis does not hold for all the major trading partners of India, indicating that intermediate goods face high barriers to trade in these sampled countries.

To this end, the main aim this paper is to investigate if there exist a long run validity of purchasing power parity and asymmetric adjustment in ASEAN-5 using the threshold cointegration test of Enders and Siklos (2001) on a set of monthly data from January, 1996 to March, 2016. Based on the results of the threshold cointegration tests, there exists a long run PPP with asymmetric adjustment in Philippines and Thailand. However, PPP does not hold in Indonesia, Malaysia and Singapore, and the adjustment process in these countries is symmetric.

\section{Econometric methodology}

\subsection{Threshold cointegration tests (TAR and MTAR)}

Following Su et al. (2010), we apply threshold cointegration technique advanced by Enders and Siklos (2001) to test for the long run PPP with asymmetric adjustment in ASEAN-5. The test is based on a two-stage process. First, we estimate a long run equilibrium relationship of the form: $e_{t}=\alpha_{0}+\beta_{1} p_{t}^{*}+\beta_{2} p_{t}+\mu_{t}$

where $e_{t}$ is the logarithm of nominal exchange rate, $p_{t}{ }^{*}$ and $p_{t}$ represent the logarithm of foreign and domestic price levels respectively and $\mu_{t}$ is the stochastic disturbance term. The second stage focuses on the OLS estimates of $\rho_{1}$ and $\rho_{2}$ in the following regression:

$\mu_{t}=I_{t} \rho_{1} \mu_{t-1}+\left(1-I_{t}\right) \rho_{2} \mu_{t-1}+\sum_{i=1}^{t} \gamma_{i} \mu_{t-1}+\varepsilon_{t}$

where $\varepsilon_{t}$ is a white-noise disturbance and the residuals, $\mu_{t}$, in Eq. 1 are extracted to Eq. 2 to be further estimated. $I_{t}$ is the Heaviside indicator function such that:

$I_{t}=\left\{\begin{array}{lll}1 & \text { if } & \mu_{t-1} \geq \tau \\ 0 & \text { if } & \mu_{t-1} \geq \tau\end{array}\right.$

where $\tau$ is the threshold value. A necessary condition for $\left\{\mu_{t}\right\}$ to be stationary is: $-2<\left(\rho_{1}, \rho_{2}\right)<0$. If the variance of $\varepsilon_{t}$ is sufficiently large, it is also possible for one value of $\rho_{j}$ to be between -2 and 0 and for the other value to equal zero. Although there is no convergence in the regime with the unit-root (i.e., the regime in which $\rho_{j}=0$ ), large realization of $\varepsilon_{t}$ will switch the system into the convergent regime. Enders and Granger (1998) and Enders and Siklos (2000) both pointed out in either case, under the null hypothesis of no convergence, the F-statistic for the null hypothesis $\rho_{1}=\rho_{2}=0$ has a nonstandard distribution. The critical values for this non-standard F-statistic are tabulated in their paper. Enders and Granger (1998) also showed that if the sequence is stationary, the least squares estimates of $\rho_{1}$ and $\rho_{2}$ have an asymptotic multivariate normal distribution.

Model using Eq. 2 is known as the threshold auto regression model (TAR), where the test for threshold behavior of the equilibrium error is termed threshold cointegration test. Assuming the system is converged, $\mu_{t}=0$ can be considered as the long-run equilibrium value of the sequence. If $\mu_{t}$ is above its long-run equilibrium, the adjustment is $\rho_{1} \mu_{t-1}$ and if $\mu_{t}$ is below its long-run equilibrium, the adjustment is $\rho_{2} \mu_{t-1}$. The equilibrium error therefore behaves like a threshold autoregression. The null hypothesis of $\rho_{1}=\rho_{2}=0$ tests for the cointegration relationship and the rejection of this null imply that existence of cointegration between variables. In revealing of $\rho_{1}=\rho_{2}=0$ hypothesis, it is valuable to further test for symmetric adjustment (i.e. $\rho_{1}=\rho_{2}$ ) by using a standard F-test. When adjustment is symmetric as $\rho_{1}=\rho_{2}$, Eq. 2 converges the prevalent augmented DF test (Said and Dickey, 1984). Rejecting both the null hypotheses of $\rho_{1}=\rho_{2}=0$ and $\rho_{1}=\rho_{2}$ imply the existence of threshold cointegration and the asymmetric adjustment.

According to Enders and Granger (1998), this model is especially valuable when adjustment is asymmetric such that the series exhibits more 'momentum' in one direction than the other. Instead of estimating Eq. 2 with the Heaviside indicator depending on the level of $\mu_{t-1}$, the decay could also 
be allowed to depend on the previous period's change in $\mu_{t-1}$. The Heaviside indicator could then be specified as:

$I_{t}=\left\{\begin{array}{lll}1 & \text { if } & \mu_{t-1} \geq \tau \\ 0 & \text { if } & \mu_{t-1}<\tau\end{array}\right.$

where $\tau$ is the threshold value. This model is termed as momentum-threshold auto regression model (MTAR). The TAR model can capture 'deep' cycle process if, for example, positive deviations are more prolonged than negative deviations. The M-TAR model allows the autoregressive decay to depend on $\mu_{t-1}$. As such, the M-TAR representation can capture 'sharp' movements in a sequence.

In the most general case, the value of $\tau$ is unknown, it needs to be estimated along with the values of $\rho_{1}$ and $\rho_{2}$. By demeaning the $\left\{\mu_{t-1}\right\}$ sequence, the Enders and Granger (1998) test procedure employs the sample mean of the sequence as the threshold estimate of $\tau$. However, the sample mean is a biased threshold estimator in the presence of asymmetric adjustments. For instance, if autoregressive decay is more sluggish for positive deviations of $\mu_{t-1}$ from $\tau$ than for negative deviations, the sample means estimator will be biased upwards. A consistent estimate of the threshold $\tau$ can be obtained by using Chan (1993) method of searching over possible threshold values to minimize the residual sum of squares from the fitted model. Enders and Siklos (2001) applied Chan's methodology to a Monte Carlo study to obtain the F-statistic for the null hypothesis of $\rho_{1}=\rho_{2}=0$ when the threshold $\tau$ is estimated using Chan's procedure. The critical values of this non-standard Fstatistic for testing the null hypothesis of $\rho_{1}=\rho_{2}=$ 0 are also tabulated in their paper. As there is generally no presumption as to whether to use TAR or M-TAR model, the recommendation is to select the adjustment mechanism by a model selection criterion such as the Akaike information criterion (AIC) or Schwartz Bayesian information criterion (SBC).

\section{Results}

We applied the threshold cointegration tests to test for the PPP hypothesis. Prior to the TAR and MTAR cointegration tests, time series unit-root tests were conducted to check for the stationarity of variables. The time series unit-root tests include the ADF and PP. Below are the results of the analyses.

Table 1 presents the results of time series unit root tests. The table shows results for Augmented Dickey-Fuller (ADF) (Said and Dickey, 1984) and Phillips-Perron (PP) (Phillips and Perron, 1988) unit root tests for the individual Asian countries (Indonesia, Philippines, Malaysia, Singapore and Thailand). The results provide evidence for unit root in the log of nominal exchange rate (lxrate) and the log of respective price levels i.e. the log of consumer price index for the Asian countries and also the log of the consumer price index for US (Lcpi and Lcpi_us) when we applied the ADF and the PP test. But after first differenced ( $\Delta$ Lxrate, $\Delta$ Lcpi and $\Delta$ Lcpi_us), these variables become stationary confirming that they are integrated of order one. Therefore, we fail to reject the null hypothesis of a unit root. Meaning that our variables of interest are not stationary at levels but stationary at first differenced.

\begin{tabular}{|c|c|c|}
\hline Country & $\mathrm{ADF}$ & PP \\
\hline \multicolumn{3}{|l|}{ Indonesia } \\
\hline Lxrate & 0.9587 & 1.1988 \\
\hline$\Delta$ Lxrate & $-5.9819 * * *$ & $-11.5332^{* * *}$ \\
\hline Lcpi & -1.0656 & -1.1106 \\
\hline$\Delta$ Lcpi & $-12.4589 * * *$ & $-20.8158^{* * *}$ \\
\hline Cpi_us & -1.2089 & -1.4259 \\
\hline$\Delta$ Cpi_us & $-10.0725^{* * *}$ & $-7.9067^{* * *}$ \\
\hline \multicolumn{3}{|c|}{ Philippines } \\
\hline Lxrate & 1.4500 & 1.1180 \\
\hline$\Delta$ Lxrate & $-13.6470^{* * *}$ & $-14.0349^{* * *}$ \\
\hline Lcpi & 0.7967 & 0.6154 \\
\hline$\Delta$ Lcpi & $-13.6470^{* * *}$ & $-13.5051^{* * *}$ \\
\hline Cpi_us & -1.2089 & -1.4259 \\
\hline$\Delta$ Cpi_us & $-10.0725^{* * *}$ & $-7.9067^{* * *}$ \\
\hline Malaysia & 0.6087 & 0.5097 \\
\hline Lxrate & $-14.7519 * * *$ & $-14.8259^{* * *}$ \\
\hline$\Delta$ Lxrate & 0.0857 & -0.0899 \\
\hline $\begin{array}{c}\mathrm{Lcpl} \\
\Delta \mathrm{Lcpi}\end{array}$ & $-14.1464^{* * *}$ & $-14.1508^{* * *}$ \\
\hline Cpi us & -1.2089 & -1.4259 \\
\hline$\Delta$ Cpi_us & $-10.0725^{* * *}$ & $-7.9067^{* * *}$ \\
\hline \multicolumn{3}{|l|}{ Singapore } \\
\hline Lxrate & -0.3430 & -0.3316 \\
\hline$\Delta$ Lxrate & $-15.9426^{* * *}$ & $-15.9513^{* * *}$ \\
\hline Lcpi & 1.1870 & -1.1332 \\
\hline$\Delta$ Lcpi & $-14.7413^{* * *}$ & $-14.7568^{* * *}$ \\
\hline Cpi_us & -1.2089 & -1.4259 \\
\hline$\Delta$ Cpi_us & $-10.0725^{* * *}$ & $-7.9067^{* * *}$ \\
\hline \multicolumn{3}{|l|}{ Thailand } \\
\hline Lxrate & 0.4380 & 0.5130 \\
\hline$\Delta$ Lxrate & $-11.9127^{* * *}$ & $-11.8658^{* * *}$ \\
\hline Lcpi & 0.0079 & 0.0862 \\
\hline$\Delta \mathrm{Lcpi}$ & $-14.7413^{* * *}$ & $-14.7568^{* * *}$ \\
\hline Cpi_us & -1.2089 & -1.4259 \\
\hline$\Delta$ Cpi_us & $-10.0725^{* * *}$ & $-7.9067^{* * *}$ \\
\hline
\end{tabular}

Furthermore, Table 2 presents the results of the threshold autoregressive (TAR) model and the momentum threshold autoregressive (MTAR) model for the case where $\tau=0$. The results failed to reject the null hypotheses of no cointegration and symmetry for all the five countries (Indonesia, Philippines, Malaysia, Singapore and Thailand) with the use of the MTAR. This implies that PPP is not valid in these countries and the adjustment process is symmetric when $\tau=0$. The results are the same for the TAR model except for the presence of asymmetric adjustment in Thailand.

However, in Table 3 where we find the results of the TAR and MTAR models in which we have consistent estimates for $\tau$, the results for all the countries considered in our sample failed to reject the null of no cointegration and symmetry for Indonesia, Philippines, Malaysia and Singapore, implying that PPP does not exist in these countries. The result is opposite for Thailand. For Thailand, the null hypotheses of no cointegration and symmetry are rejected, indicating the presence of cointegration and asymmetry adjustment. The result of Thailand 
clearly shows that PPP is valid in Thailand and the adjustment process is asymmetrical. Furthermore, looking at the result of the MTAR model, we fail to reject the null hypotheses of no cointegration and symmetry for Indonesia, Malaysia, Singapore and Thailand indicating that PPP does not hold and the adjustment process is symmetric. The result here is different for Philippines, where we reject the null hypotheses of no cointegration and symmetry indicating that PPP holds and the adjustment process towards equilibrium is asymmetric.

Table 2: Results of the TAR and MTAR when $\tau=0$

\begin{tabular}{|c|c|c|}
\hline Country & TAR & MTAR \\
\hline \multicolumn{3}{|l|}{ Indonesia } \\
\hline$\tau$ & 0 & 0 \\
\hline$\rho_{1}$ & $-0.1086^{* *}$ & $-0.1070^{* *}$ \\
\hline$\rho_{2}$ & $-0.0742^{*}$ & $-0.0751^{*}$ \\
\hline$\phi_{\mu}$ & $4.7272(7.0845)$ & $4.7038(7.6044)$ \\
\hline \multicolumn{3}{|l|}{ Philippines } \\
\hline$\tau$ & 0 & 0 \\
\hline$\rho_{1}$ & -0.0133 & -0.0142 \\
\hline$\rho_{2}$ & $-0.0307^{* * *}$ & $-0.0415^{* * *}$ \\
\hline$\phi_{\mu}$ & $4.8924(5.8040)$ & $5.7603(6.1306)$ \\
\hline $\begin{array}{c}\rho_{1}=\rho_{2} \\
\text { Malaysia }\end{array}$ & $0.8654(2.9144)$ & $2.5360(3.8532)$ \\
\hline$\tau$ & 0 & 0 \\
\hline$\rho_{1}$ & $-0.1683^{*}$ & $-0.2307^{* *}$ \\
\hline$\rho_{2}$ & -0.1262 & -0.0727 \\
\hline$\phi_{\mu}$ & $2.0100(7.0309)$ & $3.0651(7.6423)$ \\
\hline $\begin{array}{c}\rho_{1}=\rho_{2} \\
\text { Singapore }\end{array}$ & $0.1589(2.3300)$ & $2.2342(3.8703)$ \\
\hline$\tau$ & 0 & 0 \\
\hline$\rho_{1}$ & -0.0307 & -0.0518 \\
\hline$\rho_{2}$ & -0.0743 & -0.0580 \\
\hline$\phi_{\mu}$ & $1.1535(7.0825)$ & $0.9578(7.5244)$ \\
\hline $\begin{array}{c}\rho_{1}=\rho_{2} \\
\text { Thailand }\end{array}$ & $0.3823(2.2638)$ & $0.0077(3.8363)$ \\
\hline$\tau$ & 0 & 0 \\
\hline$\rho_{1}$ & -0.0859 & $-0.2194^{* *}$ \\
\hline$\rho_{2}$ & $-0.3302^{* * *}$ & $-0.1556^{*}$ \\
\hline$\phi_{\mu}$ & 6.3208 (7.0803) & $3.5700(7.6549)$ \\
\hline$\rho_{1}=\rho_{2}$ & $5.7209(2.2492)^{* *}$ & $0.3763(3.9649)$ \\
\hline $\begin{array}{r}\text { Note: } \rho_{1} \text { and } \\
\text { negative deviatio } \\
\text { cointegration, a } \\
* * * \text { indicate }\end{array}$ & $\begin{array}{l}\text { ine the speed of adjus } \\
\text { ively. } \phi_{\mu} \text { denotes the } \\
2 \text {, the statistic for the } \\
\text { ice at } 10 \%, 5 \% \text { and } 1\end{array}$ & $\begin{array}{l}\text { it for positive and } \\
\text { istic for the null of no } \\
\text { f symmetry. }{ }^{*}, * * \text { and } \\
\text { els respectively }\end{array}$ \\
\hline
\end{tabular}

\section{Conclusion}

This paper investigates whether there is a longrun purchasing power parity (PPP) with asymmetric adjustment for a group of ASEAN-5 countries for the period of 1996-2016 using the Enders and Siklos (2001) threshold cointegration (TAR and MTAR) tests. Unit-root tests were applied prior to the cointegration tests in checking the fulfilment of the data for cointegration tests. The unit-root tests revealed that all variables (exchange rate, consumer price index for each ASEAN5 and U.S.) are not stationary at levels but stationary at first difference, i.e. all variables are integrated of order 1 . Furthermore, we conducted the asymmetric cointegration test for the TAR and MTAR models when $\tau=0$. The results of these tests failed to reject the null hypothesis of no cointegration for all the countries (Indonesia, Philippines, Malaysia, Singapore and Thailand), but the null of symmetry was rejected only for Thailand (which means that all other countries have symmetric adjustment except for Thailand which is asymmetric). However, we found support for cointegration and asymmetric adjustments when we obtained estimates for $\tau$. With values for $\tau$, we conducted the asymmetric cointegration test where the null hypotheses of no cointegration and symmetry were reject for Thailand in the case of the TAR model and for Philippines with the MTAR model. Based on the results of the threshold cointegration tests, there is evidence of long run PPP with asymmetric adjustment in Philippines and Thailand. However, PPP does not hold in Indonesia, Malaysia and Singapore, and the adjustment process in these countries is symmetric. This may due to the price fluctuations in Indonesia, Malaysia and Singapore that make the local prices deviate from the price in U.S.

Table 3: Results of the TAR and MTAR with value for $\tau$

\begin{tabular}{ccc}
\hline Country & TAR & MTAR \\
\hline Indonesia & & \\
$\tau$ & 0.268492 & 0.268492 \\
$\rho_{1}$ & $-0.1272^{* *}$ & $-0.2144^{*}$ \\
$\rho_{2}$ & $-0.0711^{* *}$ & $-0.0845^{* * *}$ \\
$\phi_{\mu}$ & $5.0040(7.1971)$ & $5.1379(7.5358)$ \\
$\rho_{1}=\rho_{2}$ & $0.8963(2.2212)$ & $1.1539(3.6956)$ \\
Philippines & & \\
$\tau$ & 0.029818 & -0.002209 \\
$\rho_{1}$ & -0.0176 & -0.0132 \\
$\rho_{2}$ & $-0.0284^{* * *}$ & $-0.0719^{* * *}$ \\
$\phi_{\mu}$ & $4.6062(5.7273)$ & $8.6749(6.1271)^{* *}$ \\
$\rho_{1}=\rho_{2}$ & $0.3182(2.8302)$ & $8.1465(3.6956)^{* *}$ \\
Malaysia & & \\
$\tau$ & -0.012681 & 0.001190 \\
$\rho_{1}$ & $-0.1929^{* *}$ & $-0.2401^{* *}$ \\
$\rho_{2}$ & -0.1022 & -0.0839 \\
$\phi_{\mu}$ & $2.3037(7.2099)$ & $3.0059(7.6392)$ \\
$\rho_{1}=\rho_{2}$ & $0.7367(2.2990)$ & $2.1249(3.8052)$ \\
Singapore & & \\
$\tau$ & -0.023151 & 0.000842 \\
$\rho_{1}$ & -0.0216 & $-0.1275^{*}$ \\
$\rho_{2}$ & $-0.0921^{*}$ & -0.0291 \\
$\phi_{\mu}$ & $1.4632(7.0423)$ & $1.7789(7.3981)$ \\
$\rho_{1}=\rho_{2}$ & $0.9966(2.4322)$ & $1.6227(3.8363)$ \\
Thailand & & \\
$\tau$ & 0.019283 & 0.010440 \\
$\rho_{1}$ & -0.0578 & $-0.2839^{* *}$ \\
$\rho_{2}$ & $-0.3433^{* * *}$ & $-0.1554^{* *}$ \\
$\phi_{\mu}$ & $7.5141(7.1681)^{* *}$ & $4.0032(7.6196)$ \\
$\rho_{1}=\rho_{2}$ & $8.0394(2.2957)^{* *}$ & $1.2178(3.7836)$ \\
\hline Note: $\rho_{1}$ and $\rho_{2}$ determine the speed of adjustment for positive and \\
negative deviations respectively. $\phi_{\mu}$ denotes the F-statistic for the null of no \\
cointegration, and $\rho_{1}=\rho_{2}$ the statistic for the test of symmetry. . $^{* * * a n d}$ \\
indicate significance at $10 \%, 5 \%$ and $1 \%$ levels respectively. \\
\end{tabular}

\section{Acknowledgement}

This work is supported under the Fundamental Research Grant Scheme FRGS (203/PMATHS/6711431).

\section{References}

Bahmani-Oskooee M, Chang T, and Lee KC (2016). Panel asymmetric nonlinear unit root test and PPP in Africa. Applied Economics Letters, 23(8): 554-558.

Baum CF, Barkoulas JT, and Caglayan M (2001). Nonlinear adjustment to purchasing power parity in the post-Bretton Woods era. Journal of International Money and Finance, 20(3): 379-399. 
Beirne J (2010). International exchange rate dynamics and purchasing power parity. Ph.D. Dissertation, Brunel University, UK.

Chan KS (1993). Consistency and limiting distribution of the least squares estimator of a threshold autoregressive model. The Annals of Statistics, 21(1): 520-533.

Chen JE, Lee CY, and Goh LT (2013). Exchange rate and oil price: Asymmetric adjustment. Applied Economic Letters, 20(10): 987-990.

Enders W and Granger CWJ (1998). Unit-root tests and asymmetric adjustment with an example using the term structure of interest rates unit-rsst tests and asymmetric adjustment. Journal of Business \& Economic Statistics, 16(3): 304-311.

Enders W and Siklos PL (2001). Cointegration and threshold adjustment. Journal of Business \& Economic Statistics, 19(2): 166-176.

Haughton AY and Iglesias EM (2012). Interest rate volatility, asymmetric interest rates pass through and the monetary transmission mechanism in the Caribbean compared to US and Asia. Economic Modelling, 29(6): 2071-2089.

Kapetanios G, Shin Y, and Snell A (2003). Testing for a unit root in the nonlinear STAR framework. Journal of Econometrics, 112(2): 359-379.
Khim V and Liew S (2004). Nonlinear adjustment of asean - 5 real exchange rates: symmetrical or asymmetrical?. Economics Letters, 6(8): 1-19.

Liew VKS, Baharumshah AZ, and Chong TTL (2004). Are Asian real exchange rates stationary?. Economics Letters, 83(3): 313316.

Lu YC, Chang T, and Yu CP (2011). Long run purchasing power parity with asymmetric adjustment: Evidence from mainland China and Taiwan. Romanian Journal of Economic Forecasting, 4(1): 59-70.

Phillips PC and Perron P (1988). Testing for unit root in time series regression. Journal Article, 75(2): 335-346.

Said SE and Dickey DA (1984). Testing for unit roots in autoregressive-moving average models of unknown order. Biometrika, 71(3): 599-607.

Su CW, Horng YS, and Wu YL (2010). Asymmetric Adjustment and Long-run purchasing power parity in BRICs. Applied Economics Letters, 17(11): 1083-1087.

Tiwari AK and Shahbaz M (2014). Revisiting purchasing power parity for India using threshold cointegration and nonlinear unit root test. Economic Change and Restructuring, 47(2): 117-133. 